\title{
The Relationship between Critical Thinking and L2 Grammatical and Lexical Knowledge
}

\author{
Abbas Ali Zarei (Corresponding author) \\ Assistant professor, Imam Khomeini International University, Qazvin, Iran \\ Tel: 98-91-2281-8077_E-mail address: aazarei@ikiu.ac.ir; aazarei@yahoo.com \\ Elham Haghgoo \\ MA, Islamic Azad University, Takestan, Iran
}

Received: May 5, 2012

Accepted: May 24, 2012

Online Published: June 15, 2012

doi:10.5430/elr.v1n1p104

URL: http://dx.doi.org/10.5430/elr.v1n1p104

\begin{abstract}
The present study was conducted to investigate the relationship between critical thinking and L2 grammatical knowledge on the one hand, and the relationship between critical thinking and lexical knowledge on the other. To fulfill this objective, a 60-item vocabulary and grammar subtest of the TOEFL test and an 80-item Watson Glaser Critical Thinking questionnaire were distributed among 150 male and female Iranians studying English as a foreign language at Azad University in Takestan, Iran. Data were analyzed using Pearson correlation procedure. The result of data analysis indicated that the correlation between vocabulary and critical thinking was not statistically significant. The correlation between grammar and critical thinking was not statistically significant either, but there was a strong trend towards a positive relationship.
\end{abstract}

Keywords: Critical thinking, Grammatical knowledge, Lexical knowledge

\section{Introduction}

Critical thinking has been one of the hottest issues since the times of ancient Greece. There are various views of critical thinking. As Mason (2007) rightly claims, many philosophers have developed theories of critical thinking. Some, like Ennis (1996), argue that critical thinking comprises particular skills, such as being able to assess reasons appropriately, or to identify false arguments. Others, like Siegel (1990), claim that critical thinking is a critical attitude or disposition such as the tendency to ask investigating questions, or critical direction. According to Astleitner (2007), critical thinking is a higher-order thinking skill which includes evaluating arguments, and is a purposeful, self-regulatory judgment which ends in interpretation, analysis, evaluation, and inference. Paul and Elder (2007) maintain that critical thinking is the disciplined art of verifying that can be used as the best thinking a person is able to in any system of conditions. Dewey (2001) views critical thinking as a method of intelligent learning that employs and rewards mind.

Various studies, to some of which reference will be made shortly, have investigated different aspects of critical thinking and its implications in language learning. The purpose of the present study is to further explore the implications of critical thinking in language pedagogy by focusing on the relationship between critical thinking and L2 lexical and grammatical knowledge. It aims to answer the following research questions:

1) Is there any significant relationship between critical thinking and L2 grammatical knowledge?

2) Is there any significant relationship between critical thinking and L2 lexical knowledge?

\section{Literature Review}

Over the last few decades, many definitions of critical thinking have been offered, but there is no consensus on its definition. Kadir (2007) maintains that this lack of unity in defining critical thinking is related to different perspectives of philosophy and psychology. Actually, philosophers focus on the notion of critical thinking, while psychologists focus on the notion of critical thinking skills. 
Noddlings (2006) defines critical thinking as the use of reason in a diligent and skillful way on personal decision making, conduct, and belief, which are matters of moral or social importance, whereas Cottrell (2005) views critical thinking as a cognitive activity which is integrated with using the mind.

Paul, Elder, \& Bartell (1997) point out that the rational roots of critical thinking are ancient and go back to the teaching practice and insight of Socrates 2500 years ago. Socrates was the one who found a method of investigating and questioning that people could not logically give grounds for their assertions to knowledge. Plato, Aristotle, and the Greek skeptics followed Socrates' practice. They believed that things are often different from what they seem to be, and only the trained mind is able to see the reality of things. So, the need to think systematically emerged from this ancient Greek tradition. During the Renaissance $\left(15^{\text {th }}\right.$ and $16^{\text {th }}$ centuries $)$, a large number of scholars in Europe started to think critically about different issues such as religion, art, society, human nature, and so on, by the belief that most of the domains of human life needed search, analysis, and critique. In the $20^{\text {th }}$ century, the strong need for critical thinking in life and education was recognized. At present, the importance of critical thinking and its power have become ever more evident.

King (1995) believes that the distinctive feature of a critical thinker is having an investigative mind; good critical thinkers are actually those who ask good questions. Paul et al. (1997) maintain that self-assessment is a crucial factor to critical thinking, and only those students who learn to assess their own thinking are critical thinkers. A critical thinker is able to reflect, explore, and analyze, and can choose to think in these advanced, complicated ways. To be a critical thinker is in fact announcing our reason and intellect with our emotions, attitudes, and dispositions. In addition, Paul and Elder (2002) hold that developing critical thinking is a progressive process which requires hard work, and becoming an excellent thinker is not possible by just taking a beginning course. So, the crucial characteristics of a critical thinker demand a long-lasting period of development.

The relationship between critical thinking and learning is fairly well-documented. Paul and Elder (2005) assert that there is a key insight that makes a connection between critical thinking and learning; human thinking is the only capacity which is used to learn. We can learn well when we think well, and when we think poorly during learning, we learn poorly. Similarly, Brown and Freeman (2000) state that learning is a collaboration and a means of connection which is necessary for critical thinking. Critical thinking demands careful reading and listening, and it also endangers the peace of assumed pleasantness that manages much of people's interaction with one another. Likewise, Duron, Limbach, and Waugh (2006) maintain that active learning can make the course more pleasant for both teachers and students, and it can encourage students to think critically (p.160).

Mok (2010) claims that critical thinking consists of two important aspects. One aspect is about space of learning and the other is about classroom teaching. In terms of space of learning, it is important to organize learning in such a way that makes students actively engaged in learning. To this end, the critical thinking process should be provided for students to distinguish the critical features of different critical attitudes. In terms of classroom teaching, the effective use of teacher questions, and participation of students in authentic discussions can engage students in meaningful critical thinking processes.

As to the importance of critical thinking, Levine (2002) avows that experience may be a great teacher, but it cannot teach us much but just some repeating experiences and happenings. We learn only when we use our creativity, and it happens when we think about our experiences more than only experiencing them. In other words, thinking is very important and has impact on every aspect of our life. In much the same vein, Weiler (2004) acknowledges that critical thinking is crucial to the learning process, cognitive development, and effective information seeking. Moreover, Hale (2008) states that critical thinking can penetrate every aspect of human life if it is substantively conceived and engaged. He emphasizes the importance of critical thinking in education and claims that critical thinking and education are inter-related and inseparable. Atkinson (1997) provides four independent reasons for the importance of teaching critical thinking and adopting its pedagogies in TESOL educators' classrooms:

(a) Critical thinking may be more on the order of a non-overt social practice than a well-defined and teachable pedagogical set of behaviors;

(b) Critical thinking can be, and has been, criticized for its exclusive and reductive character;

(c) Teaching thinking to nonnative speakers may be fraught with cultural problems; and,

(d) Once taught, thinking skills do not appear to transfer effectively beyond their narrow context of instruction (p.71).

Mimbs (2005) and Halvorsen (2005) also assert that today critical thinking is an important skill in life, and that teachers need to integrate some of its key elements into their classrooms. This view is shared by others like Davidson 
(1998); Waters (2006); and Liaw (2007). Furthermore, Paul and Elder (2005) give four reasons why critical thinking is becoming more and more important: "accelerating change, intensifying complexity, escalating interdependence, and increasing danger" (p.12).

A number of factors may influence critical thinking. Moon (2008) focuses on the role of emotion, language, and curiosity in critical thinking. She asserts that emotion may have an effect on the process of critical thinking. Emotion can affect the way in which we work with the materials of learning. She also believes that curiosity has an important role in critical thinking. Actually, curious people do not accept ideas easily and try to ask more and more questions and to think critically about issues.

Another factor is gender. Research done by King, Wood, and Mines (1990) seems to indicate that the rate of development of critical thinking may be different for men and woman and that differential educational experiences may motivate men to become good critical thinkers.

Still another factor is level of education. Keeley, Browne, and Kreutzer (1982) investigated the impact of college on critical thinking ability. In general, the results of their study revealed that seniors did better than freshmen in critical thinking and that college can stimulate and provoke students' critical thinking ability.

$\mathrm{Ku}$ and Ho (2010) refer to the use of meta-cognitive strategies as another important factor to enhance critical thinking. They claim that meta-cognitive strategies invoke behaviors that make students able to control their thinking process. These meta-cognitive strategies can be divided into three categories of planning, monitoring, and evaluating. Magno (2010) also claims that meta-cognitive skills have positive influence on critical thinking skills.

A number of studies have empirically investigated the relationship between critical thinking and various areas of language. Mirzai (2008) attempted to find the relationship between critical thinking and lexical inferencing of Iranian EFL learners. To this end, 130 male and female students of a language institute were given a TOEFL and Honey critical thinking questionnaire including 30 items. The results of the study revealed that those students with high critical thinking ability outperformed the ones with low critical thinking ability in lexical inferencing.

Kamali and Fahim (2011) investigated the relationship between critical thinking ability, resilience, and reading comprehension of texts containing unknown vocabulary items. 63 intermediate EFL learners were given Honey's (2004) appraisal test, Connor and Davidson's (2003) Resilience Scale, a vocabulary checklist, and a validated battery of four reading tests. Results showed that (a) the levels of critical thinking had a significant effect on the scores of the participants on the resilience scale, (b) the levels of critical thinking had significant effect on the participants' comprehension of texts with unfamiliar vocabulary items, and (c) the levels of resilience had significant effect on the participants' comprehension of texts with unfamiliar vocabulary items.

Myers and Dyer (2006) investigated the effect of students' learning style on critical thinking skill. To this end, 135 students taking the agriculture and life sciences leadership courses at the University of Florida were chosen. The Gregorc Style Delineator was administered to assess the preferred learning style of each student. To determine the critical thinking skills of each student, the Cornell Critical Thinking test was administered. No differences were found between the critical thinking skills of male and female students. However, students with deeply embedded abstract sequential learning style preferences showed significantly higher critical thinking scores. No differences in critical thinking ability existed between students of other learning styles.

Koupaee Dar, Rahimi, and Shams (2010) investigated the importance of raising students' critical thinking through explicit teaching of some techniques of critical discourse analysis (CDA). Their study attempted to find changes in BA students' abilities in discovering the hidden layers of meaning implied in texts. There was also an attempt to reveal the possible changes both in students' views toward learning English language and in their critical language awareness (CLA) before and after teaching critical reading through CDA techniques. 60 BA-level English students at intermediate and advanced proficiency levels were chosen. Three pairs of online news articles were selected from different sources, and students were supposed to analyze them. They were also given a six-item questionnaire to elicit students' feedback after the treatment. The results showed that critical language awareness of about $90 \%$ of students and their motivation in learning English increased after becoming familiar with the field of CDA.

Birjandi and Bagherkazemi (2010) investigated the relationship between EFL teachers' critical thinking ability and their student-evaluated professional success. To this end, the critical thinking ability of 67 Iranian EFL teachers was measured through the Persian version of Watson-Glaser critical thinking appraisal. The teachers' professional success was also gauged through the successful Iranian EFL Teacher Questionnaire (SIETQ). The results of correlation and regression analyses showed a statistically significant relationship between the two sets of measures. 
Lun, Fischer, and Word (2010) investigated the cultural differences in critical thinking between Asian and European students. The results revealed that European students performed better on two objective measures of critical thinking skills than Asian students.

Sheikhi (2009) investigated the relationship between autonomy, critical thinking, and reading comprehension of Iranian EFL learners. To this end, a language proficiency test (TOEFL), a questionnaire of autonomy, a questionnaire of critical thinking (Watson-Glaser Critical Thinking Appraisal) and two reading tests were used. The result of the analyses revealed that autonomy is significantly related to critical thinking, and that there is a correlation between critical thinking and reading comprehension. The findings also showed a strong relationship between autonomy and reading comprehension.

Boloori (2010) conducted a study to evaluate the predictive power of critical thinking of Iranian English language learners on their performance on inferential reading comprehension tests. She found that there was a significant correlation between critical thinking and inferential reading comprehension.

Magno (2010) investigated the role of metacognitive skills in developing critical thinking. To this end, the Watson-Glaser Critical Thinking Appraisal and the Metacognitive Assessment Inventory were administered to 240 freshmen college students who were taking their first year in college in Philippines. In order to determine the effect of metacognition on critical thinking, the Structural Equation Modeling (SEM) was used. The Pearson Product Moment correlation procedure revealed that the factors of metacognition are significantly related to the factors of critical thinking.

\section{Method}

\subsection{Participants}

A sample of 150 pre-intermediate level EFL students (male and female) majoring in different fields other than English language at Azad University in Takestan participated in this study. The initial number of participants was then reduced to 133 after the administration of TOEFL test to homogenize them. The participants, who ranged in age from 18 to 32, were taking English as a general course.

\subsection{Instruments}

To conduct the present study, two instruments were employed: a TOEFL test and a critical thinking questionnaire (Watson Glaser Critical thinking questionnaire)

The TOEFL test was employed to determine the participants' level of English language proficiency as well as their vocabulary and grammar knowledge. It was a three-part, 100-item multiple-choice test containing 40 grammar items, 30 vocabulary items requiring selection of a synonym or completion of a sentence, and reading passages followed by 30 comprehension questions.

The Watson Glaser Critical Thinking Appraisal was used to assess the participants' critical thinking. The CTA is designed to measure some of the important abilities involved in critical thinking. The questionnaire is a reliable and standard one. Since it was designed for native speakers, to avoid any misunderstanding, the translated version of this test, prepared and validated by Yari (2004, cited in Sheikhi, 2009), was used.

\subsection{Procedures}

Initially, to homogenize the participants, a multiple-choice 100 -item TOEFL test was administered to 150 participants. The analysis of the scores indicated that 17 of the participants had to be excluded from the study due to a different proficiency level. The other ones were selected as the participants of the study. The scores of the participants on the vocabulary and grammar subtests of the same TOEFL test were used to measure the vocabulary and grammatical knowledge of the participants. Each subtest contained 30 items in multiple-choice format. Then, the Watson Glaser critical thinking questionnaire, which consisted of 80 items, was administered. To avoid any misunderstanding, its translated version was used. Having administered the tests and the questionnaire and gathered the data, to answer the research questions, two separate Pearson Correlations were run.

\section{Results}

\subsection{Investigation of the first research question}

The first question attempted to find the relationship between critical thinking and L2 grammatical knowledge. To this end, a Pearson correlation was used. Table 1 summarizes the descriptive statistics and test results for the critical thinking scores as well as the grammar scores of the participants. 
As Table 1 shows, the correlation coefficient index (0.169) is not statistically significant, but there is a strong trend towards a positive relationship.

\subsection{Investigation of the second research question}

The second question investigated the relationship between critical thinking and L2 lexical knowledge. To this end, another Pearson correlation was used. Table 2 contains the result.

Table 2 shows that the correlation coefficient of 0.141 is not statistically significant. This means that there is no significant correlation between critical thinking and L2 lexical knowledge.

\subsection{Discussion}

The findings of the present study contradict those of a number of previous studies. Kamali and Fahim (2011) found that critical thinking had significant effect on the participants' comprehension of text with learning unfamiliar vocabulary items. Mirzai (2008) also, reported that there is a significant relationship between critical thinking and lexical inferencing. This is not in accordance with the result of the present study. Moreover, Khamesian (2009) found a relationship between critical thinking skills and learners' grammar, while the result of this study revealed that the correlation between critical thinking and L2 grammatical knowledge was not statistically significant, although there was a strong positive trend.

The differences between the findings of the present study and those of other studies can be accounted for on several grounds. One possible reason for such differences may be partially attributable to the cultural differences leading to different abilities of the participants. According to the research done by Lun et al. (2010), Asian students often show more difficulties in engaging in critical thinking. Volet (1999 cited in Lun et al, ibid) maintains that different educational contexts have their own unique culture of learning. Alagozlu (2007) claims that Turkish EFL students are not strong enough to express their thoughts, especially in a foreign language, and they should be supported regarding critical thinking skills. This problem is rooted in the system of traditional education, which provides ready-made information requiring no questions. The Iranian context falls into the same category. At the beginning levels of education, students might be involved in critical thinking, but in higher levels, they are not encouraged to think critically. They do not have any courses regarding critical thinking and improving it at schools and universities. This is, in turn, due to the wider socio-cultural context in which obedience is encouraged and any inclinations toward critical thinking are suppressed. It is undeniable that culture of education and culture of society are interrelated. In societies such as Iran, people are not allowed to critique and express their opinions freely. This culture of authoritarianism is transferred to schools and universities where there is no learner-autonomy, and classes are teacher-centered.

Regarding educational context, it can be said that context of learning may affect critical thinking ability. Contrary to ESL learners, EFL learners may not be able to express their ideas easily because of their limited English language knowledge. The infirmity of educational program may also prevent the development of critical thinking by providing ready-made materials and course books which do not provoke the sense of probing in students.

Considering practical constraints, it can be said that the large number of students in classes is a problem by itself. They do not have enough time to share their ideas or ask any questions in class, so teachers have to cover the syllabus in a limited time without giving students any chance to talk. Their only concern is to cover the book, and they prefer to teach and inform their students instead of asking them to evaluate materials.

Another possible reason could be differences in the proficiency level of the participants. In this study, the participants were lower-intermediate general English students, while in studies such as Sheikhi (2009), Koupaee Dar et al. (2010), Boloori (2010) and Kamali and Fahim (2011), the participants were at intermediate and advanced proficiency levels. As it was shown by Sheikhi (2009), there is a significant direct relationship between critical thinking and autonomy. In the beginning levels, students are not familiar with language strategies, so they heavily rely on their teachers and avoid applying their own thought. But in advanced levels, students enjoy a higher level of background knowledge, learning strategies, and autonomy. That is why they are less dependent on the teacher, and less afraid of expressing themselves. Keeley et al. (1982) also, revealed that seniors performed better than freshmen in critical thinking.

\section{Conclusion}

The present study attempted to investigate the relationship between critical thinking and L2 grammatical and lexical knowledge. Few researchers have investigated such a relationship, but different studies (e.g. Sheikhi 2009; Boloori 2010; and Kamali\& Fahim 2011) have investigated the relationship between critical thinking and other language 
skills such as reading. Although they did not investigate the relationship between critical thinking and grammar or vocabulary specifically, their findings revealed that there is a significant positive relationship between critical thinking and reading comprehension. The important point is that grammar and vocabulary are two major components of reading comprehension. So, it can be concluded that if there is a relationship between critical thinking and reading, then critical thinking is expected to have positive relationship with grammar and vocabulary, too.

All in all, the above mentioned areas of conflict are probably indicative of the need for further research.

\section{References}

Alagozlu, N. (2007). Critical Thinking and Voice in EFL Writing. Asian EFL Journal, 9(3), 118-136

Allen, M. (1997). Smart thinking skills for critical understanding and writing. New York: Oxford.

Astleitner, H. (2007). Teaching Critical Thinking Online. Journal of Instructional Psychology, 29(2), 53-77.

Atkinson, D. (1997). A Critical Approach to Critical Thinking in TESOL. TESOL Quarterly, 31(1), 71-94. http://dx.doi.org/10.2307/3587975

Birjandi, P., \& Bagherkazemi, M. (2010). The relationship between Iranian EFL teachers' Critical Thinking ability and their professional success. English language Teaching, 3(2), 135-145.

Boloori, L. (2010). The relationship between critical thinking and performance of Iranian EFL learners on the inferential reading comprehension test. Unpublished master's thesis, Azad University of Takestan, Iran.

Brown, M. N., \& Freeman, K. (2000). Distinguishing the features of critical thinking classrooms. Teaching in Higher Education, 5(3), 301-309. http://dx.doi.org/10.1080/713699143

Cottrell, S. (2005). Critical thinking skills. Developing effective analysis and argument. New York: Palgrave Macmillan.

Davidson, B. W. (1998). Comments on Dwight Atkinson's "a critical approach to critical thinking in TESOL": a case for critical thinking in the English language classroom. TESOL Quarterly, 32 (1), 119-123. http://dx.doi.org/10.2307/3587906

Dewey, J. (2001). Democracy and Education. State University: Pennsylvania.

Duron, R., Limbach, B., \& Waugh, W. (2006). Critical thinking framework for any discipline. International Journal of Teaching and Learning in Higher Education, 17(2), 160-166.

Ennis, R. (1996). Critical thinking assessment. Theory into Practice, 32(3), 179-186. http://dx.doi.org/10.1080/00405849309543594

Hale, S. (2008). A critical analysis of Richard Paul's Substantive Tran-disciplinary conception of critical thinking. Unpublished doctoral dissertation, Union University of Cincinnati, Ohio.

Halvorsen, A. (2005). Incorporating critical thinking skills development into ESL/ EFL courses. The Internet TESL Journal, 11(3), 1-5.

Kadir, M. A. A. (2007). Critical thinking: A family resemblance in conceptions. Journal of Education and Human Development, 1(2), 1-11.

Kamali, Z., \& Fahim, M. (2011). The relationship critical thinking ability of Iranian EFL learners and their resilience level facing unfamiliar vocabulary items in reading. Journal of Language Teaching and Research, 2(1), 104-111. http://dx.doi.org/10.4304/jltr.2.1.104-111

Keeley, S. M., Brown, M. N., \& Kreutzer, J. S. (1982). A comparison of freshmen and seniors on general and specific essay tests of critical thinking. Research in Higher Education, 17(2), 139-154. http://dx.doi.org/10.1007/BF00973715

Khamesian, M. (2008). The relationship between critical thinking skills and writing in EFL engineering learners. Unpublished master's thesis, Islamic Azad University of Science and Research Campus, Tehran, Iran.

King, P. M., Wood, P. K., \& Mines, R. A. (1990). Critical thinking among college and graduate students. The review of Higher Education, 13(2), 167-186.

King, A. (1995). Designing the instructional process to enhance critical thinking across the curriculum. Teaching of Psychology, 22(1), 13-17. http://dx.doi.org/10.1207/s15328023top2201_5

Koupaee Dar, Z., Rahimi, A., \& Shams, M. R. (2010). Teaching reading with a critical attitude: using critical discourse analysis to raise EFL university students' critical language awareness. International Journal of Criminology and Sociology, 3(2), 457-476.

$\mathrm{Ku}, \mathrm{K}$. Y. L, \& Ho, I. T. (2010). Metacognitive strategies that enhance critical thinking. Metacognition and Learning, 5(3), 1-17. http://dx.doi.org/10.1007/s11409-010-9060-6 
Levine, P. D. (2002). Thinking about doing: on learning from experience and the flight from thinking. Human relations, 55(10), 1251-1268. http://dx.doi.org/10.1177/0018726702055010083

Liaw, M. (2007). Content-based Reading and Writing for Critical Thinking Skills in an EFL Context. English Teaching and Learning, 31(2), 45-87.

Lun, V. M., Fischer, R., \& Ward, C. (2010). Exploring cultural differences in critical thinking: Is it about my thinking style or the language I speak? Learning and Individual differences, 20, 604-616. http://dx.doi.org/10.1016/j.lindif.2010.07.001

Magno, C. (2010). The role of metacognitive skills in developing critical thinking. Metacognition Learning, 5(2),137-156. http://dx.doi.org/10.1007/s11409-010-9054-4

Mason, M. (2007). Critical thinking and learning. Educational Philosophy and Theory, 39 (4), 337-473. http://dx.doi.org/10.1111/j.1469-5812.2007.00343.x

Mimbs, C. A. (2005). Teaching from the critical thinking, problem-based curricular approach: strategies, challenges, and recommendations. Journal of Family and Consumer Sciences Education, 23(2), 7-18.

Mirzai, Z. (2008). The relationship between Critical Thinking and Lexical Inferencing of Iranian EFL Learners. Unpublished master's thesis, Azad University of Science and Research, Tehran, Iran.

Mok, J. (2010). The new role of English language teachers: developing students' critical thinking in Hong Kong secondary school classrooms. The Asian EFL Journal Quarterly, 12(2), 262-287.

Moon, J. (2008). Critical thinking. An exploration of theory and practice. London: Routledge.

Myers, B. E., \& Dyer, J. E. (2006). The influence of student learning style on critical thinking skill. Journal of Agricultural Education, 47 (1), 43-52. http://dx.doi.org/10.5032/jae.2006.01043

Noddlings, N. (2006). Critical lessons. What our schools might teach but do not. New York: Cambridge.

Paul, R., \& Elder, L. (2002). Critical thinking: tools for taking charge of your professional and personal life. Dillon Beach, CA: Foundation for Critical Thinking.

Paul, R., \& Elder, L. (2005). A guide for educators to critical thinking competency standards. Dillon Beach, CA: Foundation for critical thinking.

Paul, R., \& Elder, L. (2007). Consequential validity: using assessment to drive instruction. Dillon Beach, CA: Foundation for critical thinking.

Paul, R., Elder, L., \& Bartell, T. (1997). California teacher preparation for instruction in critical thinking: research findings and policy recommendations. Sacramento, CA: California Commission on Teacher Credentialing.

Sheikhi, B. R. (2009). The relationship between Autonomy, Critical thinking and Reading comprehension of Iranian EFL learners. Unpublished master's thesis, Azad University of Science and Research, Tehran, Iran.

Waters, A. (2006). Thinking and language learning. ELT Journal, 60(4), 319-327. http://dx.doi.org/10.1093/elt/ccl022

Weiler, A. (2004). Information-seeking behavior in generation Y students: Motivation, critical thinking, and learning theory. The Journal of Academic Librarianship, 31(1), 46-53. http://dx.doi.org/10.1016/j.acalib.2004.09.009

Table 1. Correlation results for critical thinking and grammar scores

\begin{tabular}{|l|c|c|c|c|}
\hline & N & Mean & $\begin{array}{c}\text { Std. } \\
\text { Error }\end{array}$ & $\begin{array}{c}\text { Std. } \\
\text { Deviation }\end{array}$ \\
\hline $\begin{array}{l}\text { Critical } \\
\text { thinking }\end{array}$ & 133 & 42.150 & .5851 & 6.7481 \\
\hline Grammar & 133 & 12.744 & .2951 & 3.4037 \\
\hline \multicolumn{4}{|c|}{ Pearson Correlation $=.169$} & Sig. $=.052$ \\
\hline
\end{tabular}

Table 2. Correlation results for critical thinking and vocabulary scores

\begin{tabular}{|l|c|c|c|c|}
\hline & $\mathbf{N}$ & Mean & $\begin{array}{c}\text { Std. } \\
\text { Error }\end{array}$ & $\begin{array}{c}\text { Std. } \\
\text { Deviation }\end{array}$ \\
\hline Vocabulary & 133 & 10.667 & .2374 & 2.7383 \\
\hline Critical thinking & 133 & 42.150 & .5851 & 6.7481 \\
\hline \multicolumn{4}{|c|}{ Sig. $=.106$} \\
\hline \multicolumn{2}{|c|}{ Pearson Correlation $=.141$}
\end{tabular}

